\title{
HIGH RESOLUTION X-RAY MICRO-CT OF ULTRA-THIN WALL SPACE COMPONENTS
}

\author{
D. J. Roth ${ }^{1}$, R. W. Rauser ${ }^{2}$, R. R. Bowman, ${ }^{1}$ P. J. Bonacuse, ${ }^{1}$ R. E. Martin ${ }^{3}$, I. E. Locci, ${ }^{2}$ \\ and M. Kelley ${ }^{4}$ \\ ${ }^{1}$ NASA Glenn Research Center, Cleveland, OH 44135 \\ ${ }^{2}$ University of Toledo, Toledo, $\mathrm{OH} 43606-3390$ \\ ${ }^{3}$ Cleveland State University, Cleveland, OH 44115 \\ ${ }^{4}$ NEURAL ID, 230 Twin Dolphin Drive, Suite D, Redwood City, CA 94065
}

\begin{abstract}
A high resolution micro-CT system has been assembled and is being used to provide optimal characterization for ultra-thin wall space components. The Glenn Research Center NDE Sciences Team, using this CT system, has assumed the role of inspection vendor for the Advanced Stirling Convertor (ASC) project at NASA. This article will discuss many aspects of the development of the CT scanning for this type of component, including CT system overview; inspection requirements; process development, software utilized and developed to visualize, process, and analyze results; calibration sample development; results on actual samples; correlation with optical/SEM characterization; CT modeling; and development of automatic flaw recognition software.
\end{abstract}

Keywords: Nondestructive Evaluation, NDE, Computed Tomography, Imaging, X-ray, Metallic Components, Thin Wall Inspection

PACS: $81.70 . \mathrm{Ex}$

\section{INTRODUCTION}

Space missions of long duration with limited ability to use solar power often utilize radioisotopebased thermo-electric power systems [1,2]. The planetary science decadel survey committee determined that the completion and validation of the Advanced Stirling Radioisotope Generator (ASRG) is its highest priority for near term technology investment [1]. NASA, in partnership with the Department of Energy, LockheedMartin, and Sunpower Corp., is spearheading an effort to develop an ultra-high efficiency, lower mass Stirling convertor for use with a radioisotope, reactor, or solar concentrator heat source for power on beyondearth-orbit space missions.

Although increasing both the temperature and pressure of the working fluid will place an increased burden on all components of the convertor, the thin wall complex-shaped heater head (essentially a pressure vessel containing the working gas helium) will be the most severely tested (see figure 1). To withstand the temperatures and stresses imposed on this structure, the heater head for the ASRG is fabricated from a highstrength cast superalloy $247 \mathrm{LC}$. The head has a very thin-walled section of proprietary dimension, and also contains a tapered region in which the wall gradually doubles in thickness. Being a cast alloy, it is likely that at least some regions of the starting material will contain defects such as porosity or deleterious phases.

Many of these types of defects were found in design heads by destructive methods to be below the limit of detectability of conventional NDI (non destructive inspection) techniques that were previously available. To address this, NASA GRC assembled a state-of-the-art x-ray micro-computed tomography ( $\mu \mathrm{CT}$ ) system for 
inspecting practically-sized components at very high resolution. The ability to detect these small defects is critical to the success of the program since all reliability and life predictions are based on the ability to reject parts with unacceptable levels of these features. This article focuses on the very unique aspects of $\mu \mathrm{CT}$ interrogation of this component.

\section{REQUIREMENTS}

The acceptance criteria for the heater head include the following: 1) for wall region: cracks or crack like flaws with depths greater than $0.120 \mathrm{~mm}$ shall be cause for rejection regardless of length and 2) American Welding Society Specification for Furnace Brazing [3]: for the braze joint used to attach a weld ring to the head, one of the criterion of this AWS specification is that the total measured void, or unbounded area, of the joint does not exceed $15 \%$ of the total joint area. Additionally, the ASRG program is requiring the inspection team to measure accurately flaw length and location.

\section{NASA GLENN RESEARCH CENTER CT SYSTEM}

The Microfocus X-ray Computed Tomography ( $\mu \mathrm{CT}$ ) facility is a non-destructive imaging technique designed to inspect complex-shaped parts for micron scale flaws. Multiple x-ray projection images are acquired, followed by software reconstruction techniques using the projection images to obtain crosssectional slices of the part. The cross-sectional images can be viewed individually or used to render a volume. The source is an X-ray WorX XWT-225-THE microfocus X-ray $225 \mathrm{keV}$ transmission tube $(<5$ um spot size, $25 \mathrm{~W}$ power) that produces a cone beam. The detector is a Dexela 2923 Detector $(0.0748 \mathrm{~mm}$ pitch, $29 \times 23 \mathrm{~cm}$ area, and 3888 × 3072 pixel elements). The acquisition, reconstruction, and visualization software is from NSI, Inc and 3M/Hytek, Inc. 4-axis motion control allows automated positioning and scanning. The system, shown in figure 2 , has resolution capability $>30$ line pair $/ \mathrm{mm}$.

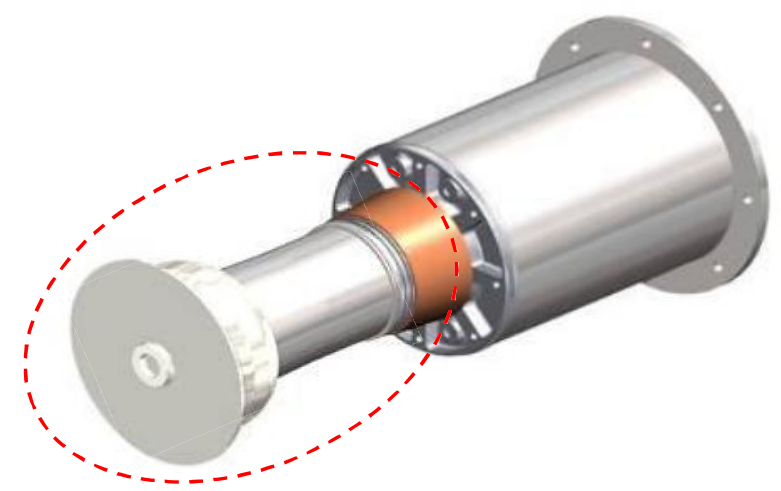

FIGURE 1. Heater head component (within ellipsed area) in Advanced Stirling Converter.
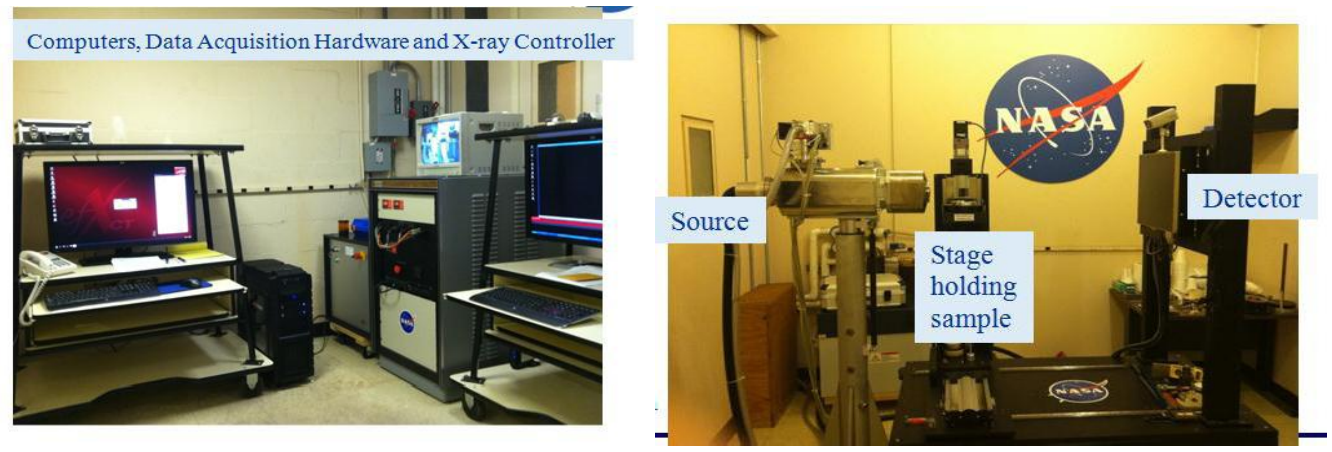

FIGURE 2. NASA Glenn Research Center X-ray CT system. 


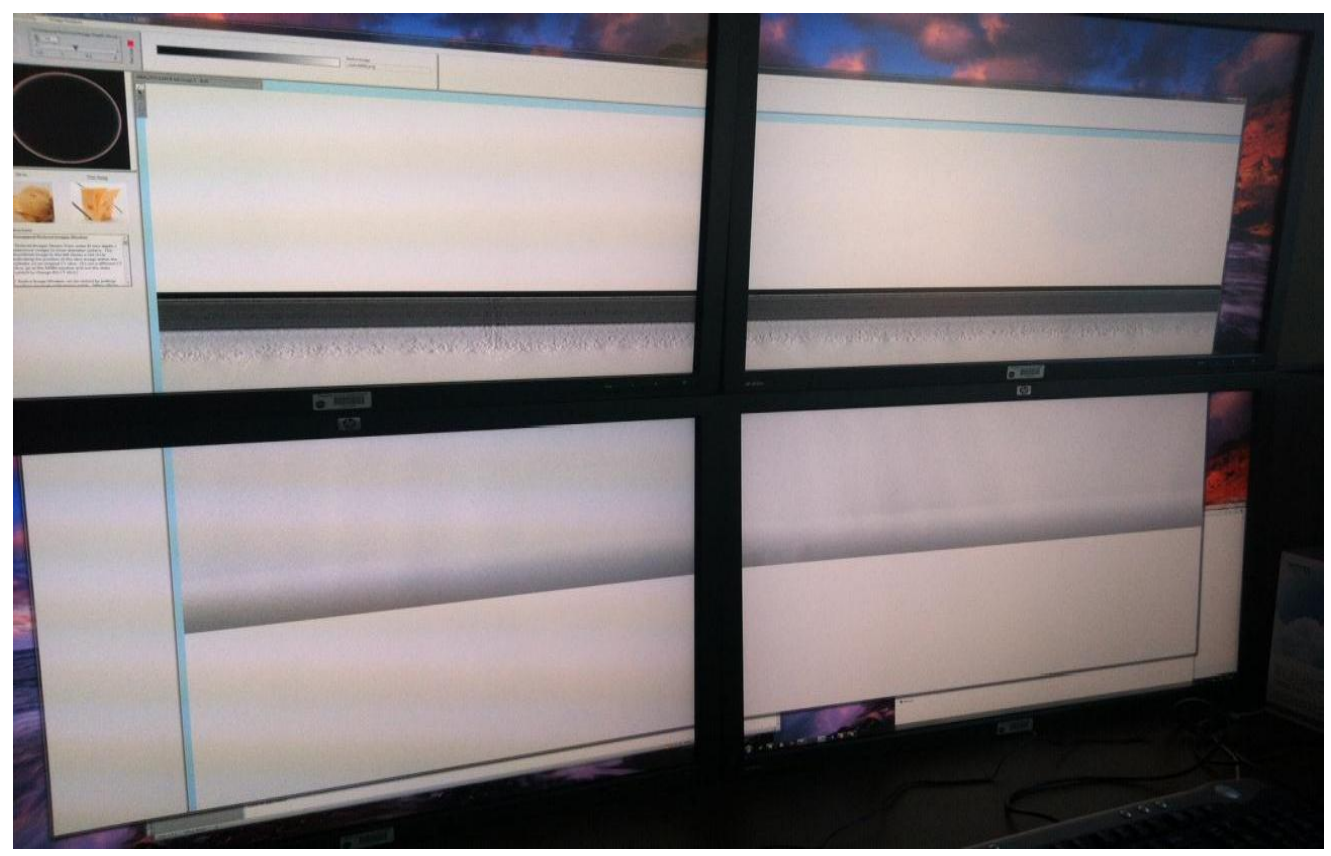

FIGURE 3. Four $x 30$ " monitor visualization setup showing unwrapped reslices spanning the four monitors.

An additional improvement to the system included the development of a reasonable-cost high resolution display system to evaluate $\mu \mathrm{CT}$ results. Because the detector has $\sim 12 \mathrm{M}$ elements, resulting slice images can be on the order of 4000 x 3000 pixels. "Unwrapped" images (to be discussed below) can be on the order of $11000 \times 3000$ pixels. This presents a significant difficulty for viewing images on a single 30 " LCD panel display that would normally be considered high resolution $(2560 \times 1600$ pixels $)$. The large images are effectively downsampled automatically in order to view on such monitors, resulting in potential lost data, which was undesirable for this project. Because of this. NASA assembled a $4 \times 30$ " display panel setup with dual video cards in an HP z800 workstation with 192 gbyte RAM resulting in 5120 x 3200 display resolution. The display is shown in figure 3. Even this is not fully adequate to view full resolution unwrapped images, but it helps greatly in image evaluation, and a display of eight large-size monitors required for no downsampling is likely impractical for any inspector to use for analysis.

\section{UNWRAPPER/RESLICER SOFTWARE}

CT data visualization in the heater head presents an immense challenge from the human factors standpoint. Most NDE methods provide one or several plots or images from which to make evaluations. For the heater head, each CT scan results in several thousand slices and a volume rendering to view. Volume rendering grayscale, texture and contrast expansion schemes that highlight the flaws of interest just serve as a baseline and must be modified for future scan results. Top view slice images for the heater head are extremely difficult to evaluate for flaw indications because the wall is so thin and the inner wall is ill-defined (see figure 4), mostly likely due to beam hardening and scattering [4]. (Beam hardening corrections were unsuccessful in defining the inner wall.)

In general for cylindrical CT data flaw detection, it can be advantageous to unwrap and reslice the $360^{\circ}$ data so as to view 2-d "sheets" from the exterior to interior of the cylinder separated by the voxel dimension. For this work, it became essential to perform this process because flaws were so difficult to detect from both top view slices and volume renderings. NASA GRC developed dedicated Computed Tomography (CT) Cylinder Unwrapper/Reslicer Software software (CT-CURS) [5] for just this purpose. Accurate lateral dimensional analysis of flaw dimensions is only possible on the unwrapped sheets. Additionally, unwrapping 


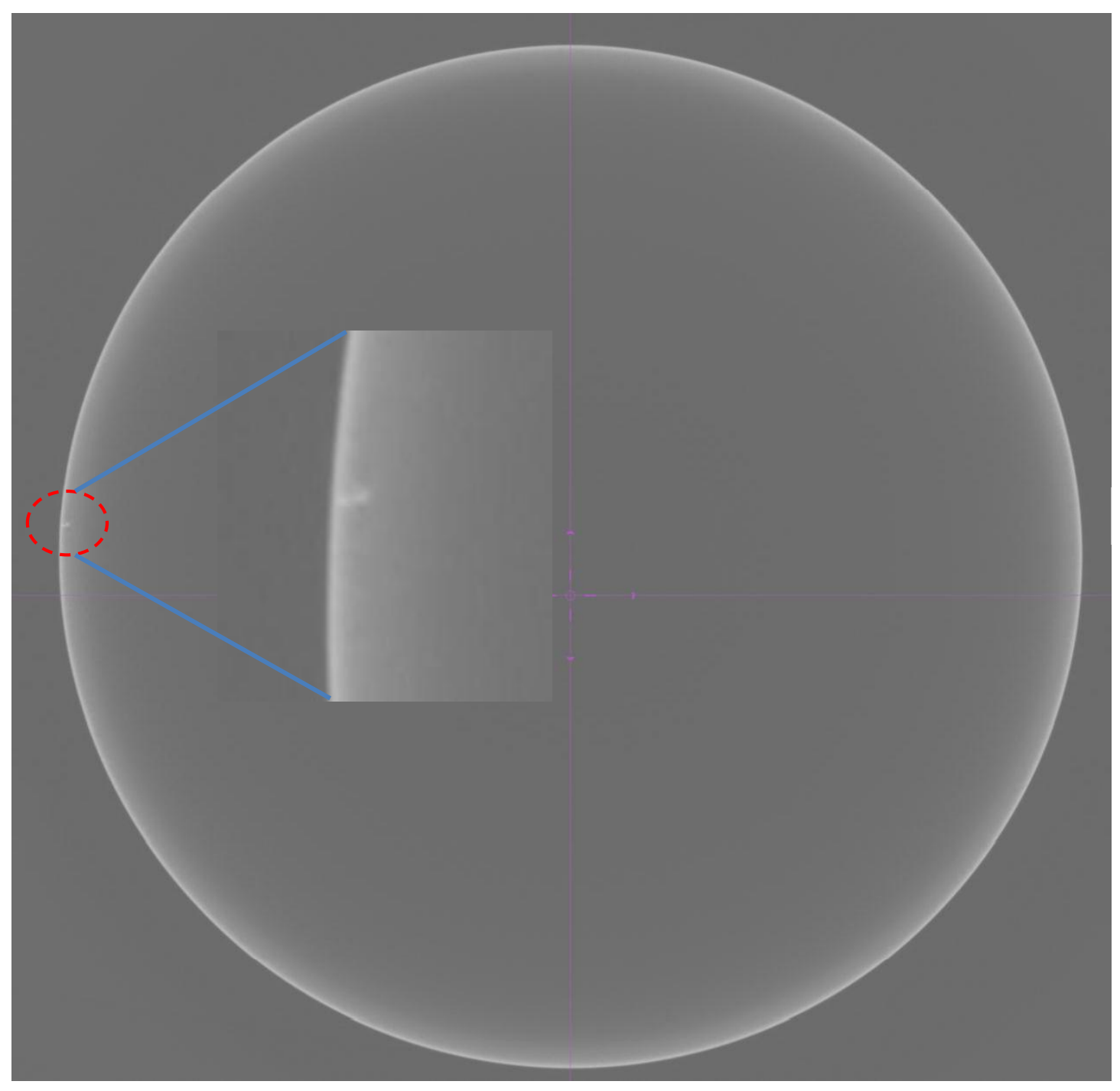

FIGURE 4. Top view CT slice of heater head showing the thin, ill-defined inner wall, and exploded view of an actual flaw found. This image illustrates the difficulty of inspecting top view CT slices for flaws.

allows the viewing of a reasonable number of large CT slices from exterior to interior of a cylindrical. Further, there is no data set size restriction when using this software which is critical for the up-to-40 gbyte data sets for the heater head. To effectively unwrap and reslice the CT data, the cross-sectional CT slices must be precisely aligned. Software to perform sub-voxel resolution alignment is included as a pre-processing step in CT-CURS. Each unwrapped reslice is contrast expanded between its minimum and maximum value, and flaws tended to "jump out" at the inspector on the reslices. Additionally, many image processing and quantitative analysis tools are available in the software to enhance flaw detectability and make flaw measurements. Figure 3 shows an unwrapped reslices spanning four monitors during an actual analysis. CTCURS is available for download by U.S. citizens at https://sr.grc.nasa.gov/public/project/86/.

\section{DEVELOPING THE CT PROCEDURE}

The goal of the procedure was to achieve maximum magnification (and therefore maximum resolution) and maximum contrast, achieve high photon flux at the detector for near-maximum dynamic range (for highest signal-to-noise ratio), and do this at reasonable tube power settings. Sufficient power would be 
required in order to allow $\mathrm{X}$-ray penetration through the weld ring ( $1 \mathrm{~mm}$ thick) in addition to the wall thickness. The optimal voltage would provide good contrast while minimizing grain scattering. A combination of voltages and currents (time) was attempted. The final experimental parameters for the heater head were source-to-object distance $=120 \mathrm{~mm}$, source-to-detector distance $=800 \mathrm{~mm}(\sim 6.7 \mathrm{x}$ geometric magnification), 3600 projection images/views (minimizing aliasing), voltage $=70 \mathrm{kV}$, and current $=200 \mu \mathrm{A}$ (14W power), $0.254 \mathrm{~mm} \mathrm{Cu}$ filter in front of tube, 4 frames / sec acquisition, 4 frame averages, calibration for every scan, optimal sharpening prior to reconstruction, and Fast Feldkamp (FDK) reconstruction. The head positioning resulted in an $11 \mu \mathrm{m}$ (very small) voxel dimension. It also resulted in very large data sets up to 40 gbyte in size. A hypodermic needle end is attached at the bottom of each head as a known measurement reference in order to verify the accuracy of flaw measurements made on the CT images. A formal procedure document was written detailing the exact steps of inspection and analysis so that all flight heater heads would be inspected in an identical fashion. Depth of the flaw was the most critical measurement. Once a flaw was located on unwrapped reslices, the vertical position correlates with the top view slice number allowing the inspector to find the correct slice, and the relative horizontal position with respect to the needle provides the angular position within the slice so that flaw can be found and its depth measured. A future version of the CT-CURS software will automatically recall the proper top view slice and mark the angular position when the user clicks on the flaw on the reslice image. An alternate method for measuring depth was by cycling through the reslices and find the starting and ending positions of the flaw indication. Uncertainty in the depth measurement was estimated at $\pm 22 \mu \mathrm{m}$ (two voxel dimensions).

\section{DEVELOPING DETECTABILITY STANDARDS}

Prior to knowing the critical-size/depth flaw specification discussed above, an excess heater head sample with a non-optimized surface finish had hole and slit flaw patterns laser-machined into it. The specification was for holes ranging in diameter from $10-70 \mu \mathrm{m}$ and ranging in depth from $50-$ full wall penetration. The slits were to range in depth from $10-30 \mu \mathrm{m}$, in width from $10-40 \mu \mathrm{m}$, and in length from $40-200 \mu \mathrm{m}$. The machined flaws did not conform to specifications, and were difficult to characterize due to the taper character and debris in the slits and holes characteristic of laser machining. Additional flaws that were machined into the excess heater head were even further out-of-conformance. However, figure 5 shows a volume rendering and one unwrapped reslice of the head with the many flaw patterns. The red-bracketed area in the volume rendering and reslice of figure 5 shows the CT representation of a hole pattern in the thin wall region that came closest to specification. All holes were easily found in the red-bracketed region at $70 \mathrm{kV}$ and $200 \mu \mathrm{A}$ settings. Attempts to create a valid heater head detectability standard based on the critical flaw depth are in process using the micro-electrical discharge method (EDM). The slits are to range in depth from $80-120 \mu \mathrm{m}$, in width from $20-70 \mu \mathrm{m}$, and length from $20 \mu \mathrm{m}-1200 \mu \mathrm{m}$. The holes are to range in depth from 80 - full wall penetration and in diameter from $20-120 \mu \mathrm{m}$.

\section{CORRELATION OF CT RESULTS WITH OPTICAL AND SEM RESULTS}

Excellent correlation between lateral flaw indications found on the CT unwrap reslices and optical and scanning electron microscope (SEM) results have been found with an example shown in figure 6.

\section{BRAZE JOINT EVALUATION}

The porosity fraction of the braze joint was evaluated per [3] again using the unwrapped reslice where the pores became most focused. The braze joint is about $0.2 \mathrm{~mm}$ thick and the CT does an excellent job of characterizing pore fraction, size, and location as shown in figure 7. The CT-CURS software has a binary threshold image processing operation to binarize the images, followed by an automated areal fraction quantitative image analysis to calculate porosity fraction. In the example shown in figure 7 , even though there is significant porosity in one area of the braze joint, the $\%$ porosity in the entire braze joint is only $2.2 \%$. 

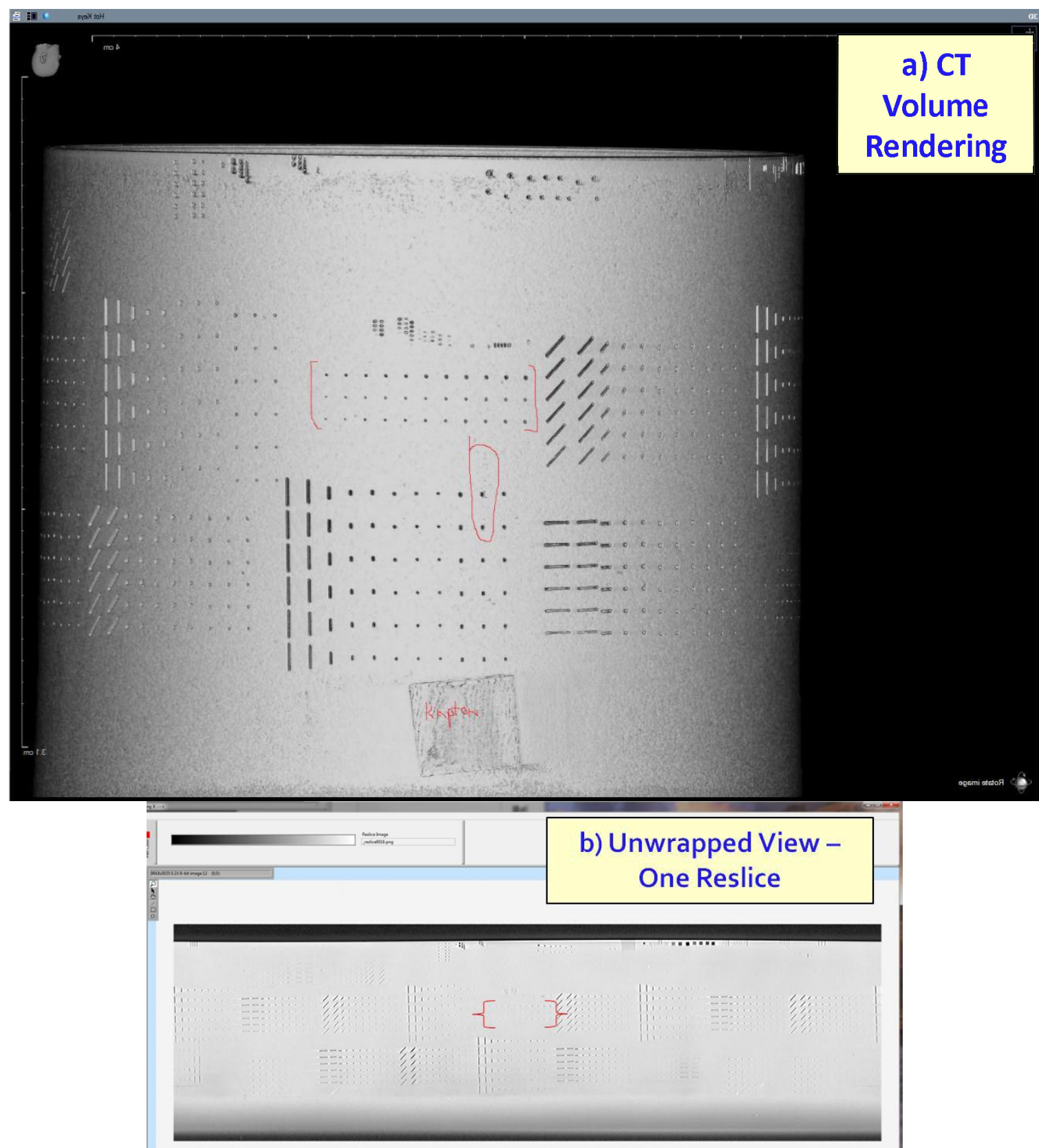

FIGURE 5. a) CT volume rendering and b) one unwrapped reslice for heater head sample with machined-in flaws. Brackets surround one flaw pattern that most closely conformed to specification.

\section{RESULTS ON ACTUAL HEATER HEAD}

Figure 8 shows results from one of the flight heater head inspections. Documentation required includes top and reslice views, volume rendering, and quantitative information on lateral size, depth, and location. 


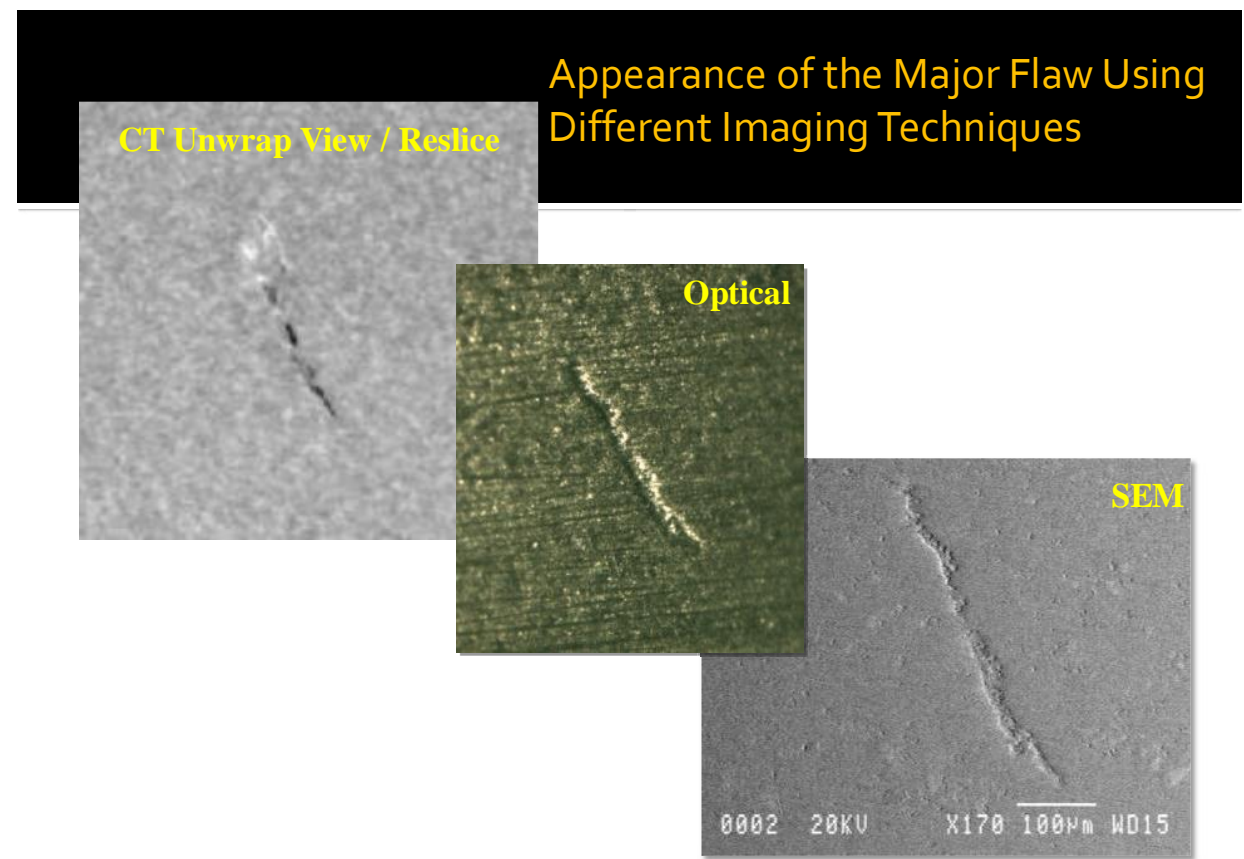

FIGURE 6. Correlation between CT, Optical, and SEM results.

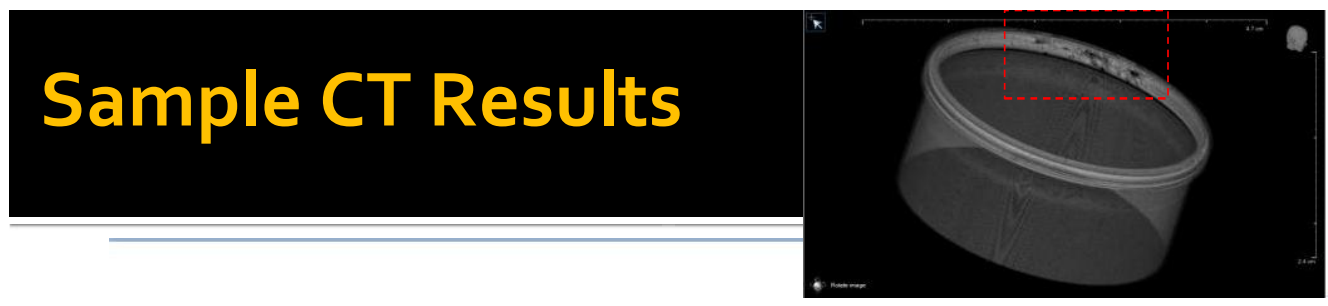

\section{Bad Braze Joint Area}
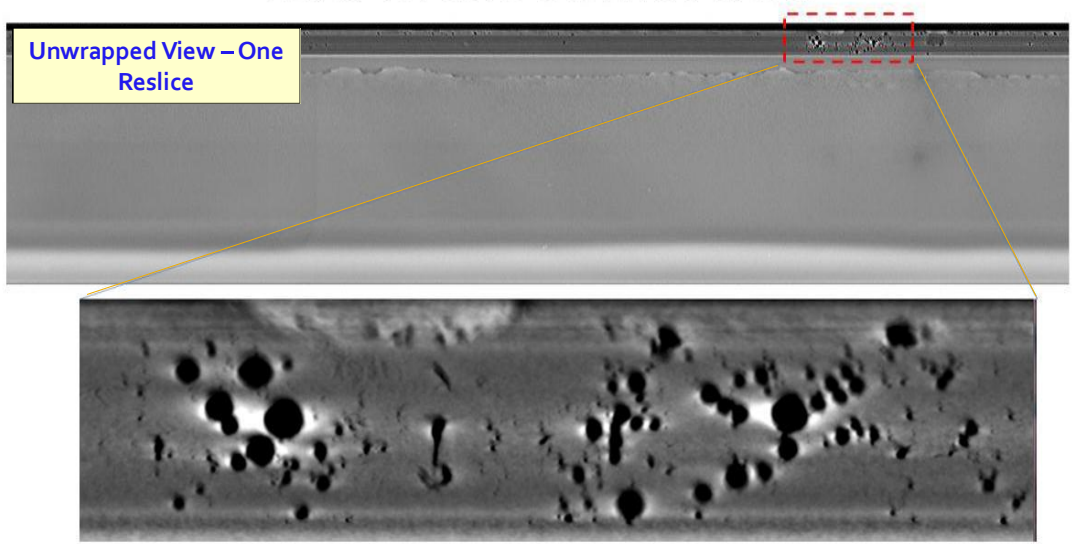

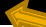

$2.2 \%$ Porosity

Binary thresholding of entire braze joint area, coloring porosity red and all other material colored black

FIGURE 7. CT volume rendering, unwrapped reslices view, and magnified view of braze joint porosity. Braze joint region of image is binarized using threshold method and areal fraction of porosity automatically calculated in CT-CURS. The \% porosity in the entire braze joint is $2.2 \%$. 

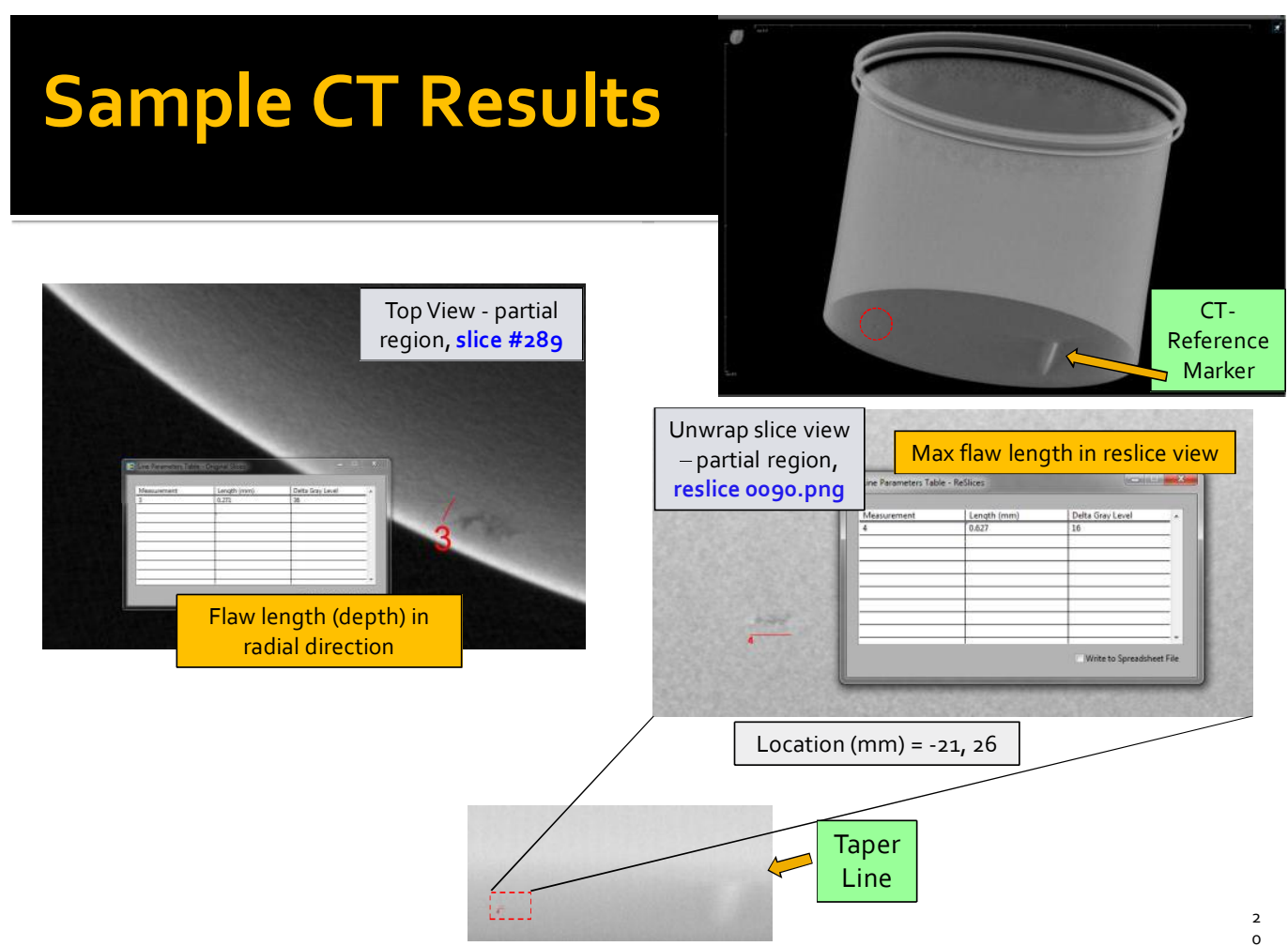

FIGURE 8. CT results on actual heater head sample including top and resclice views, volume rendering, and quantitative information on lateral size, depth, and location.

\section{ADDITIONAL CONSIDERATIONS}

NASA GRC is pursuing CT inspection modeling using CIVA v10.1 to determine the expected detection capability for the experimental setup in this inspection prior to having a valid detectability standard available for CT scanning. Modeling will be done for both the thin wall and taper regions. The flaw patterns for the new detectability standard will be incorporated into the model. Valid modeling will require accurate descriptions of specimen, source, detector, inspection setup, and flaws. Once the detectability standard is obtained and CT-scanned, results between modeling and experiment can be compared in order to validate the model. Figure 9 shows a screenshot of the setup for modeling of the head.

Since inspection is time-consuming and difficult as previously explained, an automated method for flaw detection would be highly desirable. NASA worked with Neural ID to create a software program using supervised and unsupervised neural network methods [6] for automated flaw detection. These methods showed some promise in automated flaw detection basically training on the gray scale characteristics/statistics of small regions (kernels) of the reslice images. This approach can also be considered for flaw detection in the top view slices. However, the images are so large that the automated approach is too computationally intensive and currently not rapid enough to implement as an aid to the inspector. An $\sim 1000 \mathrm{x}$ improvement in speed would be required to apply to CT image sets. NASA continues working with Neural ID, Inc. and National Instruments on strategies for speed improvements including possibly dedicated hardware. 


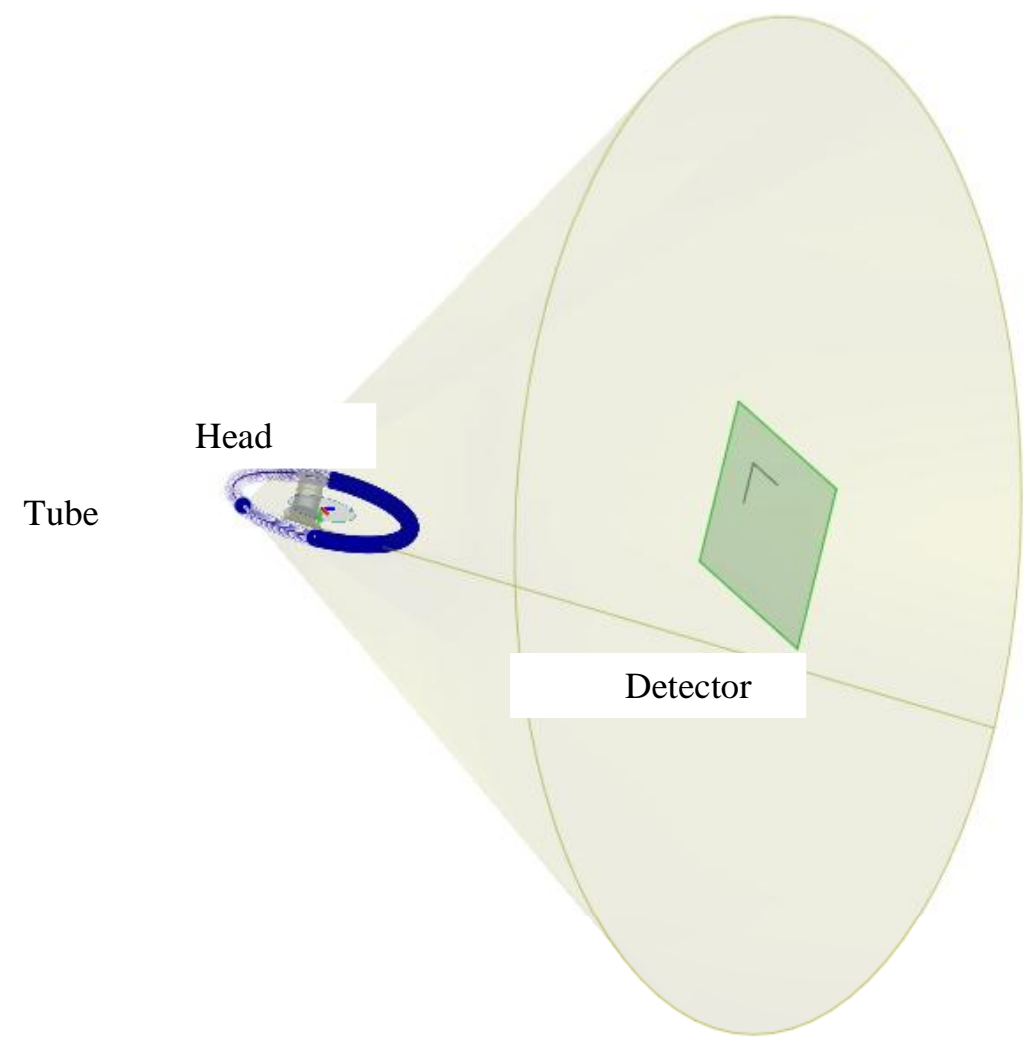

FIGURE 9. Simulation for heater head inspection showing the solid model of the heater head located in between the x-ray tube source and the detector.

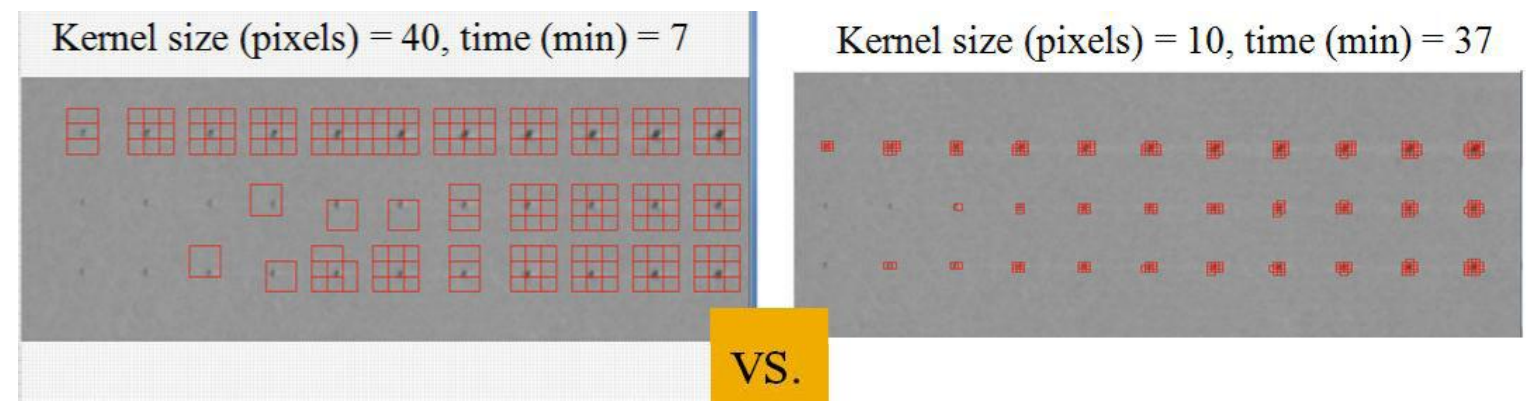

FIGURE 10. Some results for automatic flaw detection experiments using unsupervised neural network approach. Red squares show flaws detected for machined flaw pattern demarcated in figure 5.

\section{REFERENCES}

1. "NASA Space Technology Roadmaps and Priorities: Restoring NASA's Technological Edge and Paving the Way for a New Era in Space," National Research Council, National Academy Press, Washington, D.C., 2012.

2. Elmo, T., "Advanced Stirling Radioisotope Generator," Loc Publishing, 2012.

3. "Specification for Furnace Brazing," AWS specification C3.6M/C3.6:2008, Section 6.5.2, American Welding Socieity, 2008.

4. Mahesh, M., "MDCT Physics: the Basics-Technology, Image Quality and Radiation Dose, Wolters Kluwer, 2009."

5. Roth, D.J., Burke, E.R., Rauser, R.W. and Martin, R.E., "A Novel Automated Method For Analyzing Cylindrical Computed Tomography Data," Fall 2011 ASNT conference. Palm Springs Convention Center, Palm Springs, California. October $24-28$.

6. "PATTERN RECOGNITION: Neural networks ease complex pattern-recognition tasks," Vision Systems Design, Vol. 16, no. 5, May 2011. 